\title{
A survey on the attitudes of the Ayurveda medical students towards cadaver dissection
}

\author{
Abegunasekara $\mathrm{NS}^{1}$, Chandimal $\mathrm{KM}^{2}$ \\ ${ }^{\prime}$ Department of Ayurveda Basic Principles, Gampaha Wickramarachchi Ayurveda \\ Institute, University of Kelaniya. \\ ${ }^{2}$ Department of Anatomy, Faculty of Medicine, Wayamba University of Sri Lanka.
}

Cadaveric dissection is a fundamental tool in teaching anatomy. Although this facilitates students to understand the theories and the concepts of the discipline, presently cadaveric dissections seems to be reduced due to negative attitudes such as exposure to hazardous chemicals, and time consumption among other things. In this study, the attitudes of Ayurveda medical students towards the cadaveric dissection were analyzed during their BAMS (Bachelor of Ayurveda Medicine and Surgery) course.This was a cross-sectional study. Data were collected from students of Gampaha Wickramarachchi Ayurveda Institute, University of Kelaniya who have completed Anatomy course in Preclinical phase. A self-administered questionnaire in five point Likert scale was given to 110 students. This study revealed that $67 \%$ of the respondents found their first visit to the dissection hall exciting and 90\% were shocked to see the cadaver for the first time. Between $60 \%$ and $94 \%$ of students held positive attitudes towards the dissection. Ninety-four per cent of the students were determined, interested, and ready to study anatomy with cadaveric dissection. Eighty-five per cent students reported that the undergraduate curriculum should include the dissection method for teaching modality of Anatomy. Hundred per cent of students have showed a sense of gratitude to the people and/or the relatives who had donated their bodies. Although dissections have given an unpleasant experience for majority of BAMS graduates at the beginning they conclude that cadaveric dissections are an essential part of teaching Anatomy in BAMS degree program. 